\title{
PD-L1, PDK-1 and p-Akt are correlated in patients with papillary thyroid carcinoma
}

\author{
Hui Wang ${ }^{A, B}$, Zhengdong Zhang ${ }^{B, C, F}$, Zhe Yan ${ }^{B, C, F}$, Shihong Ma ${ }^{A, E, F}$ \\ Department of General Surgery, Shanghai Xuhui Center Hospital, China \\ A - research concept and design; $\mathrm{B}$ - collection and/or assembly of data; $\mathrm{C}$ - data analysis and interpretation; \\ $D$ - writing the article; $E$ - critical revision of the article; $F$ - final approval of the article
}

Address for correspondence

Shihong Ma

E-mail:msh191203@yeah.net

\section{Funding sources}

The study was funded by the Foundation for Development of Clinical Medical Science and Technology (grant №. JLY20180041) and the Research Foundation of Xuhui Center Hospital (grant No. 2018XHYY-10).

Conflict of interest

None declared

Received on February 19, 2020

Reviewed on March 6, 2020

Accepted on April 30, 2020

Published online on August 4, 2020

\begin{abstract}
Background. Papillary thyroid carcinoma (PTC) is the most common type of thyroid carcinoma.

Objectives. To investigate the clinical significance of programmed death ligand 1 (PD-L1) and phosphoinositide-dependent protein kinase 1 (PDK1) in PTC.

Material and methods. A total of 194 PTC patients were recruited. Contralateral normal thyroid tissues were obtained and used as controls $(n=80)$. The expression levels of PD-L1, PDK1 and $p$-Akt were determined using immunohistochemistry.
\end{abstract}

Results. The PD-L1, PDK1 and p-Akt were upregulated in cancer tissues compared to the normal tissues. The mean optical density (MOD) values of PD-L1, PDK1 and p-Akt were significantly higher in the PTC tissues. The expression of PD-L1 positively correlated with the levels of PDK1 and p-Akt. In addition, the expression of PD-L1, PDK1 and p-Akt in PTC patients without chronic lymphocytic thyroiditis (CLT) was significantly higher than the expression of those proteins in the CLT patients. The patients with higher expression levels of PD-L1, PDK1 or p-Akt had remarkably larger tumors and higher rates of TNM III-IV, capsular infiltration, lymph node metastasis, and of recurrence. The Kaplan-Meier curve showed that patients with lower expression of PD-L1, PDK1 or p-Akt had significantly longer recurrence-free time. The logistic regression analysis revealed that only CLT, PD-L and capsular infiltration were risk factors for patients' five-year recurrence.

Conclusions. The PD-L1, PDK1 and p-Akt were found to be positively correlated with a poor prognosis in PTC.

Key words: prognosis, papillary thyroid carcinoma, p-Akt, SPD-L1, PDK-1

\section{Cite as}

Wang H, Zhang Z, Yan Z, Ma S. PDK-1 and p-Akt are correlated in patients with papillary thyroid carcinoma. Adv Clin Exp Med. 2020;29(7):785-792. doi:10.17219/acem/121518

DOI

10.17219/acem/121518

\section{Copyright}

Copyright by Author(s)

This is an article distributed under the terms of the

Creative Commons Attribution 3.0 Unported (CC BY 3.0)

(https://creativecommons.org/licenses/by/3.0/) 


\section{Introduction}

Papillary thyroid carcinoma (PTC) is the most common type of thyroid carcinoma. ${ }^{1,2}$ It accounts for about $70-85 \%$ of all thyroid carcinoma cases. ${ }^{3,4}$ Compared to other types of thyroid carcinomas, such as follicular thyroid carcinoma (FTC) and anaplastic thyroid carcinoma (ATC), PTC has a better prognosis with a five-year survival rate of over $90 \% .^{5,6}$ However, lymph node metastasis and recurrence are very common in PTC patients. ${ }^{7}$ Recurrence has been reported in 15-30\% of cases and lymph node metastasis occurs in 5-10\% of PTC patients. ${ }^{8,9}$ For these patients, the five-year survival rate is only about $50 \% .^{10}$

Chronic lymphocytic thyroiditis (CLT), also known as Hashimoto's thyroiditis, is an autoimmune disease characterized by a painless and diffuse goiter, occasionally accompanied by atypical symptoms, such as hyperthyroidism, exophthalmos, hypothyroidism, etc. ${ }^{11}$ The relationship between CLT and PTC has been reported in recent years. Previous studies have shown that PTC patients with concurrent CLT had better prognoses than those without CLT. ${ }^{12,13}$ However, a deeper understanding of the relationship between PTC and CLT is still needed.

Programmed death ligand 1 (PD-L1), also known as CD274, is a cell surface glycoprotein that belongs to the B7 family. ${ }^{14}$ It plays important roles in many cancers, such as non-small-cell lung cancer and pancreatic cancer. ${ }^{15,16}$ Recent evidence has revealed that PD-L1 was upregulated in PTC emerging from CLT and was correlated with metastasis. ${ }^{17}$ However, the clinical significance of PDL1 in PTC remains unclear. In addition, another study found that PD-L1 was correlated with the phosphoinositide/dependent protein kinase 1 (PDK1), the phosphorylation of Akt in ovarian cancer. ${ }^{18}$ However, to the best of our knowledge, no study has focused on the relationship between PD-L1, PDK1 and p-Akt in PTC patients with or without CLT.

We aimed to perform an observational study to investigate the clinical significance of PD-L1, PDK1 and p-Akt in PTC patients. Our data showed that PD-L1, PDK1 and p-Akt were upregulated in PTC patients, especially those without CLT, and that the high expression of PD-L1, PDK1 and p-Akt was correlated with a poor prognosis of PTC. These findings might provide clinical evidence for the potential application of PD-L1, PDK1 and p-Akt as biomarkers in PTC diagnosis.

\section{Material and methods}

\section{Patients}

The present study included 194 patients with PTC who went to our hospital between April 2011 and October 2014, and met the inclusion criteria. All patients were first diagnosed with PTC using histological analysis. The exclusion criteria were as follows: receiving chemotherapy or radiotherapy before the study; other thyroid diseases apart from CLT, such as nodular goiter; other immune diseases; and other cancers or papillary thyroid microcarcinoma. In addition, 80 contralateral normal thyroid tissue samples were obtained from the same patients and all were confirmed to be healthy tissues through histological analysis. The study was approved by the Ethic Committee of Shanghai Xuhui Center Hospital, China.

\section{Immunohistochemistry}

The expression levels of PD-L1, PDK1 and p-Akt were determined using immunohistochemistry (IHC). Briefly, tissues were collected immediately after resection and stored at $-20^{\circ} \mathrm{C}$ before being used. After the samples were fixed with $10 \%$ formalin, embedded in paraffin and sectioned, hematoxylin and eosin $(\mathrm{H} \& \mathrm{E})$ staining was performed. The samples were then immersed in $3 \% \mathrm{H}_{2} \mathrm{O}_{2}$ followed by incubation with primary antibodies - anti-PD-L1 (ab205921; Abcam, Cambridge, UK), anti-PDK1 (ab90444; Abcam), or anti-p-Akt (ab38449; Abcam) - at $4^{\circ} \mathrm{C}$ overnight. After being incubated with a corresponding second antibody at $37^{\circ} \mathrm{C}$ for $30 \mathrm{~min}$, the samples were stained with diaminobenizidine (DAB). Some sections were treated with phosphate-buffered saline (PBS) instead of primary antibody and were used as negative controls. Sections with a high expression of PD-L1, PDK1 or p-Akt served as positive controls. The Allred scoring system was used for pathological scoring. The degrees of staining intensity were the following: 0 (no staining); 1 (weak staining); 2 (moderate staining); and 3 (strong staining). Scores for the percentage of stained area were as follows: 0 (none); 1 (<1\%); 2 (1-10\%); 3 (10-33\%); 4 (33-66\%); and 5 (>66\%). Both were used as the final IHC score: $0-2$ (negative); $3-4$ (weak); 5-6 (moderate); and 7-8 (strong). To further determine the expression levels of PD-L1, PDK1 and p-Akt, semi-quantitative analysis was conducted by calculating the mean optical density (MOD) using Image Pro Plus v. 6.0 software (Media Cybernetics, Rockville, USA). Briefly, photographs were collected at a magnification of $\times 400$ under the same exposure conditions. Five random photographs were captured for each slice. The integrated optical density (IOD) was calculated. For pictures with no blank area, MOD = IOD/picture area; for pictures with a blank area, $\mathrm{MOD}=\mathrm{IOD} /$ (picture area - blank area). The MOD value of 1 slice was calculated as the mean value of the 5 randomly selected fields in the slice.

\section{Data collection}

The basic characteristics of all patients were collected, including age, sex and body mass index (BMI). The clinical variables - including TNM (tumor-nodule-metastasis) stage, tumor diameter, capsular infiltration, tumor number, and lymph node metastasis - were also recorded. 
All patients were followed up for 5 years from admission. To analyze the recurrence rate, the recurrence-free time was calculated during the study period from admission to death or to the end of follow-up.

\section{Statistical analysis}

The measurement data are expressed as means \pm standard deviation (SD). Comparisons between 2 groups of continuous data were performed using Student's t-test. The $\chi^{2}$ test was used to compare the categorical variables. Pearson's correlation analysis was performed to analyze the correlation of PD-L1, PDK1 and p-Akt. For recurrence analysis, Kaplan-Meier curve was used with the log-rank test. For logistic analysis, logistic regression was conducted using the stepwise method. A p-value $<0.05$ was considered to be statistically significant. All data analysis was performed using SPSS v. 22.0 software (IBM Corp., Armonk, USA).

\section{Results}

\section{Basic characteristics of all patients}

The basic characteristics of the patients are listed in Table 1. Among the 194 PTC patients, 68 had CLT and 126 were without concurrent CLT. The ratio of female patients in the PTC+CLT group was significantly higher and the mean age of the patients was significantly lower than in the patients without CLT ( $\mathrm{p}<0.05$; Table 1). The PCT

Table 1. Basic characteristics of all patients

\begin{tabular}{|c|c|c|c|}
\hline Variables & $\begin{array}{l}\text { PTC without } \\
\text { CLT, } n=126\end{array}$ & $\begin{array}{c}\mathrm{PTC}+\mathrm{CLT} \\
\mathrm{n}=68\end{array}$ & $p$-value \\
\hline Age [years] & $48.76 \pm 9.48$ & $42.30 \pm 10.27$ & $<0.001$ \\
\hline Sex, female (\%) & $86(68.25)$ & $57(83.82)$ & 0.008 \\
\hline BMI $\left[\mathrm{kg} / \mathrm{m}^{2}\right]$ & $22.92 \pm 3.00$ & $23.39 \pm 3.09$ & 0.307 \\
\hline \multicolumn{3}{|c|}{ TNM stage, n (\%) } & \multirow{3}{*}{0.002} \\
\hline$|-| \mid$ & $67(53.17)$ & $50(73.53)$ & \\
\hline III-IV & $59(46.83)$ & $18(26.47)$ & \\
\hline Mean diameter $[\mathrm{cm}]$ & $2.21 \pm 0.69$ & $1.92 \pm 0.61$ & $<0.001$ \\
\hline \multicolumn{3}{|c|}{ Capsular infiltration, n (\%) } & \multirow{3}{*}{$<0.001$} \\
\hline yes & $79(62.70)$ & $25(36.76)$ & \\
\hline no & $47(37.30)$ & $43(63.24)$ & \\
\hline \multicolumn{3}{|c|}{ Number of tumors, n (\%) } & \multirow{3}{*}{0.684} \\
\hline$\geq 6$ & $17(13.49)$ & $10(14.71)$ & \\
\hline$<6$ & $109(86.51)$ & $58(85.29)$ & \\
\hline \multicolumn{3}{|c|}{ Lymph node metastasis, n (\%) } & \multirow{3}{*}{0.034} \\
\hline yes & $69(54.76)$ & $27(39.71)$ & \\
\hline no & $57(45.24)$ & $41(60.29)$ & \\
\hline
\end{tabular}

BMI - body mass index; PTC - papillary thyroid carcinoma; CLT - chronic lymphocytic thyroiditis. patients with CLT showed significantly lower rates of TNM III-IV, capsular infiltration and lymph node metastasis, as well as markedly smaller tumor diameter than those without CLT ( $\mathrm{p}<0.05)$. However, there was no significant difference in the number of tumors between the 2 groups.

\section{Expression of PD-L1, PDK1 and p-Akt was upregulated and positively correlated in PTC patients}

The expression levels of PD-L1, PDK1 and p-Akt were determined with IHC and the MOD values were assessed. As shown in Fig. 1, the expression levels of PD-L1, PDK1 and p-Akt were upregulated in the cancer tissues and remained low in the normal tissues. Similarly, the MOD values of PD-L1, PDK1 and p-Akt were significantly higher in PTC tissues compared with the controls $(\mathrm{p}<0.05)$. Moreover, the expression of PD-L1, PDK1 and p-Akt in PTC patients without CLT was markedly higher than that in patients with CLT $(\mathrm{p}<0.05)$. The Pearson's analysis revealed that the levels of PD-L1 and PDK1, PD-L1 and p-Akt, and PDK1 and p-Akt were positively correlated in all tissues $(\mathrm{p}<0.05$; Table 2$)$.

Table 2. Expression of PD-L1 and PDK1, PD-L1 and p-Akt, and PDK1 and $\mathrm{p}$-Akt were positively correlated

\begin{tabular}{|l|c|c|c|c|}
\hline Proteins & $\begin{array}{c}\text { Statistical } \\
\text { variables }\end{array}$ & PD-L1 & PDK1 & p-Akt \\
\hline PD-L1 & $\begin{array}{c}\text { Pearson's } \\
\text { correlation }\end{array}$ & 1 & 0.542 & 0.585 \\
\hline PDK1 & $\begin{array}{c}\text { p-value } \\
\text { Pearson's } \\
\text { correlation }\end{array}$ & - & 0.000 & 0.000 \\
\hline P-Akt & $\begin{array}{c}\text { p-value } \\
\text { Pearson's } \\
\text { correlation }\end{array}$ & 0.000 & - & 0.556 \\
\hline
\end{tabular}

PD-L1 - programmed death ligand 1; PDK1 - phosphoinositidedependent protein kinase 1.

\section{PD-L1, PDK1 and p-Akt levels correlated with patients' clinical outcomes}

To further study the roles of PD-L1, PDK1 and p-Akt in PTC, the clinical characteristics of all patients were analyzed. The PTC patients were divided into high/ low PD-L1 groups according to the MOD value of PDL1 (0.023), as well as high/low PDK1 groups and high/ low p-Akt groups according to the MOD values of PDK1 (0.021) and p-Akt (0.022). The results showed that patients with high expression of PD-L1, PDK1 or p-Akt had significantly more cases of TNM III-IV ( $<<0.05$; Tables $3-5$ ). Furthermore, the percentage of patients with capsular infiltration, lymph node metastasis and five-year recurrence 

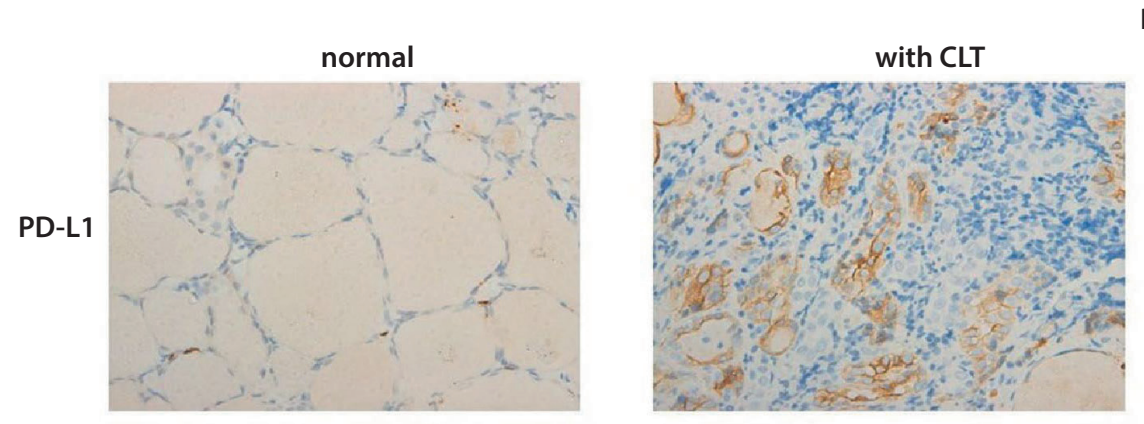

PTC
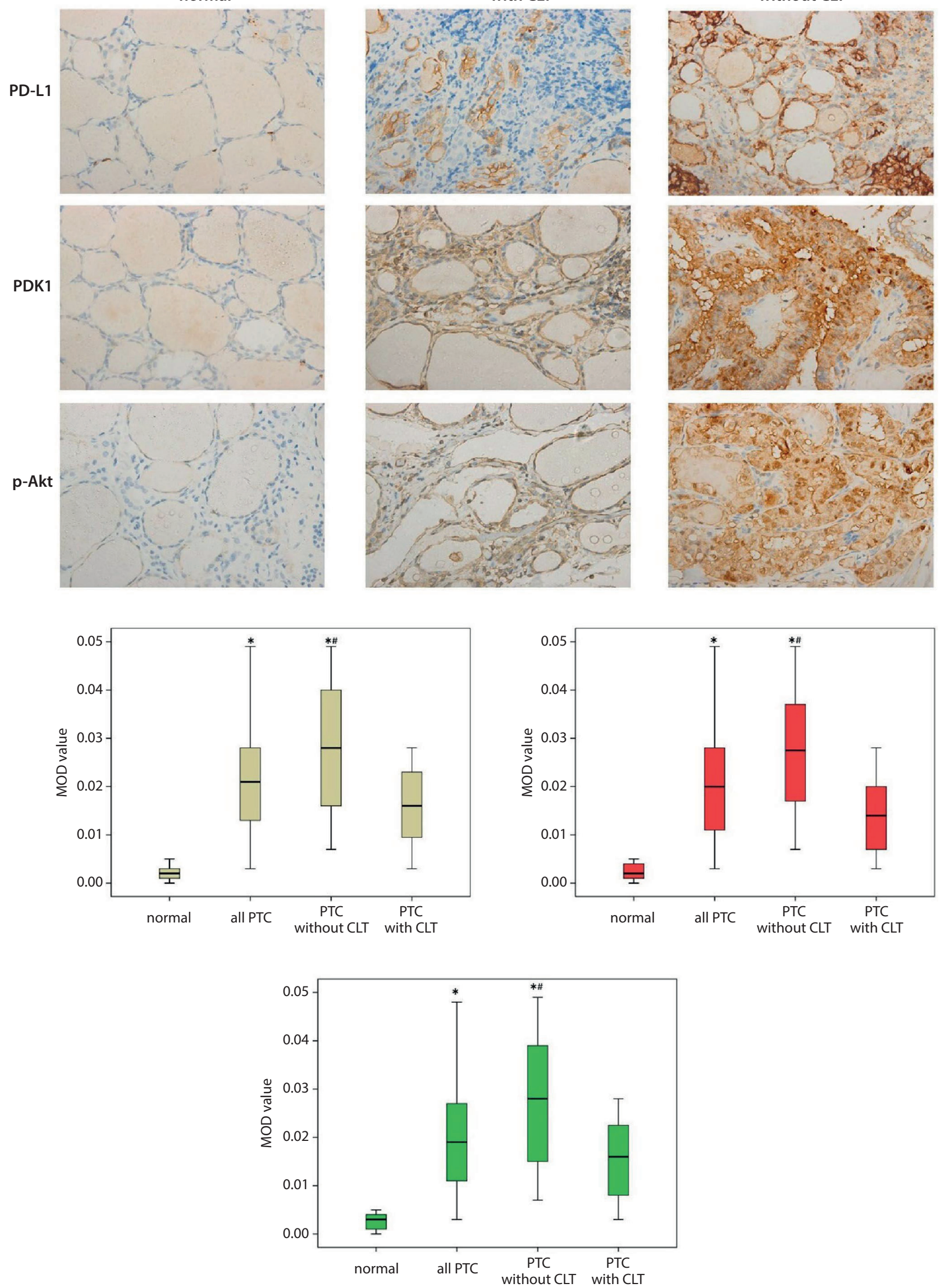

Fig. 1. Expressions of PD-L1, PDK1 and p-Akt were upregulated and positively correlated in PTC patients 
Table 3. PD-L1 correlated with patients' clinical outcomes

\begin{tabular}{|c|c|c|c|}
\hline Variables & $\begin{array}{l}\text { High PD-L1 } \\
\quad(n=92)\end{array}$ & $\begin{array}{l}\text { Low PD-L1 } \\
(n=102)\end{array}$ & $p$-value \\
\hline Age [years] & $47.35 \pm 10.46$ & $45.64 \pm 9.94$ & 0.247 \\
\hline Sex, female (\%) & $69(75.00)$ & $74(72.55)$ & 0.694 \\
\hline $\mathrm{BMI}\left[\mathrm{kg} / \mathrm{m}^{2}\right]$ & $23.19 \pm 2.86$ & $22.98 \pm 3.22$ & 0.638 \\
\hline \multicolumn{3}{|c|}{ TNM stage, n (\%) } & \multirow{3}{*}{0.011} \\
\hline$|-| \mid$ & $47(51.09)$ & $70(68.63)$ & \\
\hline III-IV & $45(48.91)$ & $32(31.37)$ & \\
\hline Mean diameter $[\mathrm{cm}]$ & $2.13 \pm 0.67$ & $2.09 \pm 0.69$ & 0.672 \\
\hline \multicolumn{3}{|c|}{ Capsular infiltration, n (\%) } & \multirow{3}{*}{0.005} \\
\hline yes & $59(64.13)$ & $45(44.12)$ & \\
\hline no & $33(35.87)$ & $57(55.88)$ & \\
\hline \multicolumn{3}{|c|}{ Number of tumors, n (\%) } & \multirow{3}{*}{0.733} \\
\hline$\geq 6$ & $12(13.04)$ & $15(14.71)$ & \\
\hline$<6$ & 80 (86.95) & 87 (85.29) & \\
\hline \multicolumn{3}{|c|}{ Lymph node metastasis, n (\%) } & \multirow{3}{*}{0.000} \\
\hline yes & $61(66.30)$ & $35(34.31)$ & \\
\hline no & $32(34.70)$ & $67(65.69)$ & \\
\hline MOD of PDK1 & $0.023 \pm 0.011$ & $0.021 \pm 0.013$ & 0.155 \\
\hline MOD of p-Akt & $0.025 \pm 0.012$ & $0.020 \pm 0.011$ & 0.005 \\
\hline Five-year recurrence, n (\%) & $17(17.53)$ & $7(6.86)$ & 0.021 \\
\hline
\end{tabular}

BMI - body mass index; MOD - mean optical density;

PD-L1 - programmed death ligand 1.

Table 4. PDK1 correlated with patients' clinical outcomes

\begin{tabular}{|c|c|c|c|}
\hline Variables & $\begin{array}{l}\text { High PDK1 } \\
\quad(n=97)\end{array}$ & $\begin{array}{l}\text { Low PDK1 } \\
(\mathrm{n}=97)\end{array}$ & $p$-value \\
\hline Age [years] & $47.42 \pm 10.36$ & $45.57 \pm 10.04$ & 0.209 \\
\hline Sex, female (\%) & $69(71.13)$ & $74(76.29)$ & 0.407 \\
\hline BMI $\left[\mathrm{kg} / \mathrm{m}^{2}\right]$ & $22.93 \pm 3.14$ & $23.24 \pm 2.94$ & 0.480 \\
\hline \multicolumn{3}{|c|}{ TNM stage, n (\%) } & \multirow{3}{*}{0.025} \\
\hline$|-| \mid$ & $51(52.58)$ & $66(68.04)$ & \\
\hline III-IV & $46(47.42)$ & $31(31.96)$ & \\
\hline Mean diameter $[\mathrm{cm}]$ & $2.24 \pm 0.72$ & $1.98 \pm 0.61$ & 0.008 \\
\hline \multicolumn{3}{|c|}{ Capsular infiltration, n (\%) } & \multirow{3}{*}{0.041} \\
\hline yes & $59(60.82)$ & $45(46.39)$ & \\
\hline no & $38(39.18)$ & $52(53.61)$ & \\
\hline \multicolumn{3}{|c|}{ Number of tumors, n (\%) } & \multirow{3}{*}{0.528} \\
\hline single & $82(84.54)$ & $85(87.63)$ & \\
\hline multiple & $15(15.46)$ & $12(12.37)$ & \\
\hline \multicolumn{3}{|c|}{ Lymph node metastasis, n (\%) } & \multirow{3}{*}{0.013} \\
\hline yes & $56(57.73)$ & $39(40.21)$ & \\
\hline no & $41(42.27)$ & $58(59.79)$ & \\
\hline MOD of PD-L1 & $0.027 \pm 0.012$ & $0.020 \pm 0.012$ & 0.001 \\
\hline MOD of $p-A k t$ & $0.025 \pm 0.013$ & $0.021 \pm 0.011$ & 0.063 \\
\hline Five-year recurrence, n (\%) & $18(18.56)$ & $6(6.19)$ & 0.008 \\
\hline
\end{tabular}

$\mathrm{BMI}$ - body mass index; MOD - mean optical density;

PDK1 - phosphoinositide-dependent protein kinase 1.
Table 5. p-Akt correlated with patients' clinical outcomes

\begin{tabular}{|c|c|c|c|}
\hline Variables & $\begin{array}{l}\text { High p-Akt } \\
\qquad(n=96)\end{array}$ & $\begin{array}{l}\text { Low p-Akt } \\
\qquad(\mathrm{n}=98)\end{array}$ & $p$-value \\
\hline Age [years] & $48.12 \pm 10.34$ & $44.90 \pm 9.89$ & 0.028 \\
\hline Sex, female (\%) & $68(70.83)$ & $75(76.53)$ & 0.360 \\
\hline BMI $\left[\mathrm{kg} / \mathrm{m}^{2}\right]$ & $22.75 \pm 2.94$ & $23.42 \pm 3.10$ & 0.120 \\
\hline \multicolumn{3}{|c|}{ TNM stage, n (\%) } & \multirow{3}{*}{0.008} \\
\hline$|-| \mid$ & $49(51.04)$ & $68(69.39)$ & \\
\hline III-IV & $47(48.96)$ & $30(30.61)$ & \\
\hline Mean diameter [cm] & $2.20 \pm 0.70$ & $2.01 \pm 0.64$ & 0.054 \\
\hline \multicolumn{3}{|c|}{ Capsular infiltration, n (\%) } & \multirow{3}{*}{0.028} \\
\hline yes & $59(61.46)$ & $45(45.92)$ & \\
\hline no & $37(38.54)$ & $53(54.08)$ & \\
\hline \multicolumn{3}{|c|}{ Number of tumors, n (\%) } & \multirow{3}{*}{0.472} \\
\hline single & $81(84.38)$ & $86(88.76)$ & \\
\hline multiple & $15(15.63)$ & $12(12.24)$ & \\
\hline \multicolumn{3}{|c|}{ Lymph node metastasis, n (\%) } & \multirow{3}{*}{0.042} \\
\hline yes & $54(56.25)$ & $41(41.84)$ & \\
\hline no & $42(43.75)$ & $57(58.16)$ & \\
\hline MOD of PD-L1 & $0.026 \pm 0.013$ & $0.021 \pm 0.012$ & 0.003 \\
\hline MOD of PDK1 & $0.025 \pm .0012$ & $0.020 \pm 0.011$ & 0.008 \\
\hline Five-year recurrence, n (\%) & $17(17.71)$ & $7(7.14)$ & 0.023 \\
\hline
\end{tabular}

$\mathrm{BMI}$ - body mass index; MOD - mean optical density.

were significantly higher in patients with high expression levels of PD-L1, PDK1 or p-Akt than the ones with low expression $(\mathrm{p}<0.05)$. The mean diameter of PTC tumors in patients with high expression of PDK1 was significantly higher than that in the group with low PDK1 expression, while no significant difference in tumor diameter was observed in the patients with high/low PD-L1 or high/low $\mathrm{p}$-Akt $(\mathrm{p}<0.05)$. Additionally, the age of the patients with lower expression of p-Akt was markedly lower than the age of the patients with high p-Akt expression $(\mathrm{p}<0.05)$. All of these results indicate that PD-L1, PDK1 and p-Akt expression levels correlate with the clinical outcomes of PTC patients.

\section{PD-L1, PDK1 and p-Akt expression correlated with patients' recurrence}

Finally, we analyzed the correlation between PD-L1, PDK1 and p-Akt expression, and the recurrence of PTC patients. The recurrence-free time was analyzed using the Kaplan-Meier curve (Fig. 2). Patients with lower expression levels of PD-L1, PDK1 or p-Akt had significantly longer recurrence-free time compared to the ones with high expression levels $(\mathrm{p}<0.05)$. Then logistic regression showed that only CLT, PD-L1 and capsular infiltration were risk factors for patients' five-year recurrence (Table 6). 
Table 6. PD-L1 and PDK1 correlated with patients' recurrence

\begin{tabular}{|l|c|c|c|c|}
\hline \multicolumn{1}{|c|}{ Variable } & Wald & OR & $95 \% \mathrm{Cl}$ & p-value \\
\hline Age & 2.261 & 0.039 & $1.040(0.988-1.094)$ & 0.133 \\
\hline BMI & 1.190 & -0.105 & $0.900(0.746-1.087)$ & 0.275 \\
\hline Diameter & 0.119 & 0.128 & $1.137(0.549-2.355)$ & 0.730 \\
\hline Sex & 1.294 & 0.835 & $2.306(0.547-9.727)$ & 0.255 \\
\hline CLT & 6.622 & 1.943 & $0.143(0.033-0.629)$ & 0.010 \\
\hline $\begin{array}{l}\text { TNM stage } \\
\text { Capsular } \\
\text { infiltration }\end{array}$ & 1.066 & -0.549 & $0.578(0.204-1.637)$ & 0.302 \\
\hline $\begin{array}{l}\text { Number } \\
\text { of tumors }\end{array}$ & 0.476 & 0.487 & $1.627(0.408-6.484)$ & 0.490 \\
\hline $\begin{array}{l}\text { Lymph node } \\
\text { metastasis }\end{array}$ & 0.327 & -0.318 & $0.728(0.245-2.162)$ & 0.567 \\
\hline PD-L1 & 7.808 & 60.801 & $12.545(7.66-8.453)$ & 0.005 \\
\hline PDK1 & 3.660 & 43.209 & $5.829(0.347-9.794)$ & 0.056 \\
\hline p-Akt & 0.658 & 15.821 & $1.902(0.000-2.975)$ & 0.417 \\
\hline
\end{tabular}

BMI - body mass index; CLT - chronic lymphocytic thyroiditis; PD-L1 - programmed death ligand 1; PDK1 - phosphoinositide-dependent protein kinase 1; OR - odds ratio; $95 \% \mathrm{Cl}$ - 95\% confidence interval.

\section{Discussion}

With the development of surgical and chemotherapy methods, the five-year survival condition for PTC patients has been greatly improved. ${ }^{19}$ However, lymph node metastasis commonly occurs in PTC patients, who often have poor prognosis. Thus, the early diagnosis of PTC is of great significance. In this study, we found that PD-L1, PDK1 and p-Akt were upregulated in PTC tissues, especially in patients without CLT, and that this upregulation correlated with a poor prognosis of the PTC patients.

The involvement of PD-L1 has been reported in many cancers. Tanaka et al. demonstrated that ERO1- $\alpha$ promoted immune escape by elevating PD-L1 in breast cancer. ${ }^{20}$ It was also reported that poly(ADP-ribose)polymerase (PARP) inhibitor enhanced cancer-associated immunosuppression by upregulating PD-L1. ${ }^{21}$ Chintakuntlawar et al. demonstrated that high PD-L1 expression in anaplastic thyroid cancer trended toward worse progression-free survival and overall survival. ${ }^{22}$ In a more recent study, upregulation of PD-L1 was found in PTC patients and the high expression of PD-L1 predicted shorter diseasefree time in these patients. ${ }^{23}$ In medullary thyroid carcinoma, however, the expression of PD-L1 was low, indicating the controversial role of PD-L1 in human cancers. ${ }^{24}$ In this study, we found that PD-L1 was upregulated in PTC patients. Moreover, the expression of PD-L1 was higher in PTC patients without CLT. PD-L1 was also found to be positively correlated with PDK1 expression, and high expression of PD-L1 was related to poor prognosis in PTC patients.

The PDK1 is an important protein in the development of multiple cancers. Zhang et al. reported that dicumarol
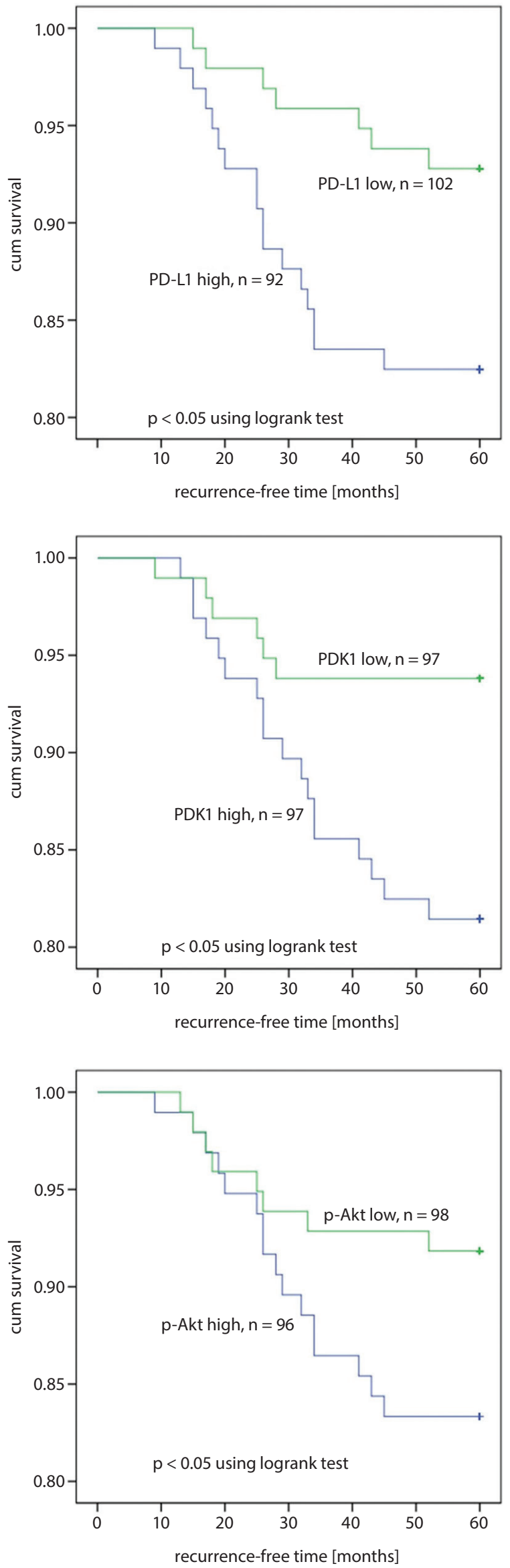

Fig. 2. The recurrence-free time in PTC patients was analyzed using Kaplan-Meier curve 
facilitated the progression of ovarian cancer by suppressing PDK $1 .{ }^{25}$ It was found that PDK1 induced the invasion and migration of gallbladder cancer. ${ }^{26}$ Fujiwara et al. reported that the inhibition of PDK1 could also be considered as a novel therapeutic target in multiple myeloma. ${ }^{27}$ In this study, we demonstrated for the first time that a high expression level of PDK1 correlated with poor prognosis and positively correlated with the expression of PD-L1 in PTC patients.

Additionally, the relationship between PD-L1 and PDK1 was also observed in several previous studies. Recent data showed that aberrant upregulation of PDK1 was correlated with the overexpression of PD-L1, ${ }^{18}$ which was consistent with our data. The p-Akt is the downstream protein of PDK1, which is also reported to play important roles in PTC. A recent study found that Akt inhibitor suppressed the proliferation of PTC cells. ${ }^{28}$ Also, the activation of the Akt signaling pathway promoted the development of PTC. ${ }^{29}$ Consistent with the above in vitro studies, we showed that the expression of p-Akt was upregulated in PTC tissues and that it predicted worse prognosis of PTC. We also found that the expression of p-Akt was higher in patients without CLT. Further investigations are needed to elucidate the molecular mechanism underlying the regulation of PD-L1, PDK1 and p-Akt in PTC progression.

The present study has some limitations. Firstly, the sample size was small. Secondly, only PTC patients were included. Other histological types of thyroid carcinoma were not investigated. Thirdly, the molecular mechanisms of PD-L1, PDK1 and p-Akt in PTC development are not clear yet and their relationship with CLT needs to be clarified.

\section{Conclusions}

This observational study evaluated the clinical significance of PD-L1, PDK1 and p-Akt in PTC. The results show that PD-L1, PDK1 and p-Akt were upregulated in PTC patients, and their expression levels were higher in patients without CLT. The high expression of PD-L1, PDK1 and p-Akt correlated with poor prognosis of PTC. This study provided clinical evidence for the potential use of PD-L1, PDK1 and p-Akt as novel potential biomarkers in PTC diagnosis.

\section{ORCID iDs}

Hui Wang (1) https://orcid.org/0000-0002-0045-8797

Zhengdong Zhang (ㄱ) https://orcid.org/0000-0002-1033-4763

Zhe Yan (1) https://orcid.org/0000-0002-4823-3327

Shihong Ma (D) https://orcid.org/0000-0002-5548-9777

\section{References}

1. Abdullah MI, Junit SM, Ng KL, Jayapalan JJ, Karikalan B, Hashim OH. Papillary thyroid cancer: Genetic alterations and molecular biomarker investigations. Int J Med Sci. 2019;16(3):450-460.
2. Liang J, Cai W, Feng D, et al. Genetic landscape of papillary thyroid carcinoma in the Chinese population: Somatic mutational profile of PTC in China. J Pathol. 2017;244(2):215-226.

3. Lim H, Devesa SS, Sosa JA, Check D, Kitahara CM. Trends in thyroid cancer incidence and mortality in the United States, 1974-2013. JAMA. 2017;317(13):1338-1348.

4. Lai $X, X i a Y$, Zhang B, et al. A meta-analysis of Hashimoto's thyroiditis and papillary thyroid carcinoma risk. Oncotarget. 2017;8(37):62414-62424.

5. Chen JP, Bai J, Yang K. Prognostic value of cervical lymph node metastasis ratio in Asian papillary thyroid carcinoma 5-year relapse-free survival: A meta-analysis. Int Jof Clin Exp Med. 2018;11(3):1401-1410.

6. Dincel O, Bayraktar C. Evaluation of platelet indices as a useful marker in papillary thyroid carcinoma. Bratis/ Lek Listy. 2017;118(3):153-155.

7. Ji WS, Han K, Lee J, et al. Application of metabolomics in prediction of lymph node metastasis in papillary thyroid carcinoma. PLoS One. 2018;13(3):e0193883.

8. Haugen BR, Alexander EK, Bible KC, et al. 2015 American Thyroid Association Management Guidelines for Adult Patients with Thyroid Nodules and Differentiated Thyroid Cancer. Thyroid. 2016;26(1):1-133.

9. Arianpoor A, Asadi M, Amini E, Ziaeemehr A, Ahmadi Simab S, Seyed Zakavi SR. Investigating the prevalence of risk factors of papillary thyroid carcinoma recurrence and disease-free survival after thyroidectomy and central neck dissection in Iranian patients. Acta Chir Belg. 2019;120(3):173-178.

10. Liu W, Cheng R, Su Y, et al. Risk factors of central lymph node metastasis of papillary thyroid carcinoma: A single-center retrospective analysis of 3273 cases. Medicine (Baltimore). 2017;96(43):e8365.

11. Vita R, leni A, Tuccari G, Benvenga $S$. The increasing prevalence of chronic lymphocytic thyroiditis in papillary microcarcinoma. Rev Endocr Metab Disord. 2018;19(4):301-309.

12. Pilli T, Toti P, Occhini R, et al. Chronic lymphocytic thyroiditis (CLT) has a positive prognostic value in papillary thyroid cancer (PTC) patients: The potential key role of Foxp3+ T lymphocytes. J Endocrinol Invest. 2018;41(6):703-709.

13. Resende de Paiva C, Grønhøj C, Feldt-Rasmussen U, von Buchwald C. Association between Hashimoto's thyroiditis and thyroid cancer in 64,628 patients. Front Oncol. 2017;7:53.

14. Trotter DEG, Meng $X, M c Q u a d e ~ P$, et al. In vivo imaging of the programmed death ligand 1 by $18 \mathrm{~F}$ positron emission tomography. J Nucl Med. 2017;58(11):1852-1857.

15. Rehman JA, Han G, Carvajal-Hausdorf DE, et al. Quantitative and pathologist-read comparison of the heterogeneity of programmed death-ligand 1 (PD-L1) expression in non-small cell lung cancer. Mod Pathol. 2017;30(3):340-349.

16. Nomi T, Sho M, Akahori T, et al. Clinical significance and therapeutic potential of the programmed death-1 ligand/programmed death-1 pathway in human pancreatic cancer. Clin Cancer Res. 2007;13(7): 2151-2157.

17. Lubin D, Baraban E, Lisby A, Jalali-Farahani S, Zhang P, Livolsi V. Papillary thyroid carcinoma emerging from Hashimoto thyroiditis demonstrates increased PD-L1 expression, which persists with metastasis. Endocr Pathol. 2018;29(4):317-323.

18. Wang JJ, Siu MK, Jiang, YX, et al. Aberrant upregulation of PDK1 in ovarian cancer cells impairs CD8+ T cell function and survival through elevation of PD-L1. Oncoimmunology. 2019;8(11):e1659092.

19. Boos LA, Schmitt $A$, Moch $H$, et al. MiRNAs are involved in tall cell morphology in papillary thyroid carcinoma. Cancers (Basel). 2019;11(6):885.

20. Tanaka T, Kutomi G, Kajiwara T, et al. Cancer-associated oxidoreductase ERO1-a promotes immune escape through upregulation of PD-L1 in human breast cancer. Oncotarget. 2017;8(15):24706-24718.

21. Jiao S, Xia W, Yamaguchi H, et al. PARP inhibitor upregulates PD-L1 expression and enhances cancer-associated immunosuppression. Clin Cancer Res. 2017;23(14):3711-3720.

22. Chintakuntlawar AV, Rumilla KM, Smith CY, et al. Expression of PD-1 and PD-L1 in anaplastic thyroid cancer patients treated with multimodal therapy: Results from a retrospective study. J Clin Endocrinol Metab. 2017;102(6):1943-1950.

23. Aghajani M, Roberts T, Yang T, et al. Elevated levels of soluble PD-L1 are associated with reduced recurrence in papillary thyroid cancer. Endocr Connect. 2019;8(7):1040-1051.

24. Bongiovanni M, Rebecchini C, Saglietti C, et al. Very low expression of PD-L1 in medullary thyroid carcinoma. Endocr Relat Cancer. 2017;24(6):L35-L38. 
25. Zhang W, Su J, Xu H, et al. Dicumarol inhibits PDK1 and targets multiple malignant behaviors of ovarian cancer cells. PLoS One. 2017;12(6): e0179672.

26. Lian SX, Shao YB, Liu HB, et al. PDK1 induces JunB, EMT, cell migration and invasion in human gallbladder cancer. Oncotarget. 2015;6(30): 29076-29086.

27. Fujiwara $\mathrm{S}$, Kawano $\mathrm{Y}$, Yuki $\mathrm{H}$, et al. PDK1 inhibition is a novel therapeutic target in multiple myeloma. Br J Cancer. 2013;108(1):170-178.
28. LeBoeuf B, Anderson B, Young M, Franco A, MacDonald L. Evaluating the effectiveness of MAPK, AKT, and mTOR inhibitors in reducing proliferation in cellular models of papillary and follicular thyroid cancer [abstract]. Cancer Res. 2018;78(13 Suppl):2887.

29. Xu J, Cai J, Jin X, et al. PIG3 plays an oncogenic role in papillary thyroid cancer by activating the PI3K/AKT/PTEN pathway. Oncol Rep. 2015;34(3):1424-1430. 